\title{
Evaluation of Requirements for Volt/Var Control and Optimization Function in Distribution Management Systems
}

\author{
Rahimi, Saaed; Marinelli, Mattia; Silvestro, Federico
}

Published in:

Proceedings of 2012 IEEE International Energy Conference and Exhibition

Link to article, DOI:

10.1109/EnergyCon.2012.6347777

Publication date:

2012

Link back to DTU Orbit

Citation (APA):

Rahimi, S., Marinelli, M., \& Silvestro, F. (2012). Evaluation of Requirements for Volt/Var Control and Optimization Function in Distribution Management Systems. In Proceedings of 2012 IEEE International Energy Conference and Exhibition (pp. 331-336). IEEE. https://doi.org/10.1109/EnergyCon.2012.6347777

\section{General rights}

Copyright and moral rights for the publications made accessible in the public portal are retained by the authors and/or other copyright owners and it is a condition of accessing publications that users recognise and abide by the legal requirements associated with these rights.

- Users may download and print one copy of any publication from the public portal for the purpose of private study or research.

- You may not further distribute the material or use it for any profit-making activity or commercial gain

- You may freely distribute the URL identifying the publication in the public portal 


\title{
Evaluation of requirements for Volt/Var Control and Optimization function in Distribution Management Systems
}

\author{
S. Rahimi, Member, IEEE, M. Marinelli, Member, IEEE and F. Silvestro, Member, IEEE
}

\begin{abstract}
To meet the requirement from new visions within "smart grid" and to provide solutions for many challenges that DSOs (Distribution System Operators) are facing today, we need to develop advanced DMS (Distribution Management System) applications. A centralized Volt/Var Control (VVC) is one of the most desirable and important functions within Distribution Automation systems and DMSs.

The overall Volt/Var control function is concerned with maintaining system voltage profile within a desired range and minimizing system losses by controlling the reactive power flow.

The main objective of this paper is to review and evaluate the existing and recent techniques and algorithms for advanced VVC applications and identify the requirements for integrated Volt/Var control and optimization function in distribution management systems within the smart grid concepts.
\end{abstract}

Index Terms--Distribution systems, integrated volt/var control (IVVC), VVC, Volt/Var Optimization (VVO), Optimization methods.

\section{INTRODUCTION}

$\mathrm{D}$ ISTRIBUTION networks used to be operated as passive systems (with almost no local generation or dispatchable generation). But the operating scenarios are going to be very different for DSOs (Distribution System Operator), due to number of reasons. Now there are considerable amount of generations from renewable resources which are connected to the network mainly at medium or distribution level. This means that distribution management systems must be ready for new paradigms in operation and control.

To provide solutions for many challenges that DSOs are facing today, it is needed to develop advanced DMS (Distribution Management System) applications, especially with new visions within "smart grid" frame. One major drive for smart Grid is the ability to reduce system losses and improve grid efficiency. Achieving this goal is possible with reducing the ohmic loss (which is major part of system loss). As a well-known problem, the ohmic loss is the result of current flow through the conductors and is proportional to the

Saeed Rahimi is currently lead engineer on EMS/ SCADA at Ventyx an ABB company, EMS/GMS group, SE-72164 Västerås, Sweden (e-mail: saeed.rahimi@ventyx.abb.com). Saeed is currently pursuing to PhD degree at University of Genoa.

Federico Silvestro is Assistant Professor and Mattia Marinelli is Post-Doc Researcher at University of Genoa, Italy (e-mail: federico.silvestro@unige.it and mattia.marinelli@unige.it). conductor resistance and the square of the current magnitude. Conductor resistance is a characteristic parameter and itself proportional to the size of conductor and resistivity of the material. So there is not much possibility for the distribution system operator to improve the conductor resistance to alleviate the ohmic loss. In return, it is possible to work on current flow as a key parameter. The current has an active component (in phase with the terminal voltage) and a reactive component (orthogonal in phase to the terminal voltage phasor angle). To reduce the ohmic loss, it is needed to alleviate the reactive component which occupies the energy delivery capacity of the conductors. A lower reactive power component of the current flowing into the conductor, means a reduction of the reactive power flowing throughout the distribution network and consequently a reduction of the ohmic loss. In conclusion, for optimizing the movement of electric energy, it is necessary to minimize the reactive power flows, which is done locally by reactive power compensation equipments such as capacitor banks.

By developments in automation and communications and ICT, it is possible to implement centralized, coordinated voltage control systems. The main challenge is that the so called Volt/Var Optimization application has comparatively high computing requirements. For providing useful solutions in near real time scale, it is necessary to develop new methodologies. The advanced VVO application will be utilizing two-way communication infrastructure and remote control capability for capacitor banks and voltage regulating transformers, to optimize the energy delivery efficiency at distribution level.

In this paper we review and evaluate the existing and recent techniques and algorithms for advanced VVO applications and identify the requirement for integrated Volt/Var Control and Optimization function for Distribution Management Systems within smart grid concept. In section 2 the physical problem is discussed and some background is given to the problem. Different available approaches to Volt /Var Control and also different optimization methods are reviewed and discussed in section 3 and 4 respectively. Finally the future requirements and the perspectives to the Volt/Var control and optimization concept are discussed in section 5 .

\section{PROBLEM DESCRIPTION AND BACKGROUND}

The basic function of voltage regulation in the distribution 
system is to provide a stable steady state voltage level within an acceptable range with all loading conditions. Due to the nature of power system, there are different levels of voltage drop between generators and end user loads. Since the voltage drop is proportional to the magnitude of demand current and the entire impedance between the source and the customer, there is larger voltage drop for the customer with large power demand or the one which receives its power through larger impedance [1]. A typical voltage profile along a feeder supplying residential loads is shown in Figure 1 [2].

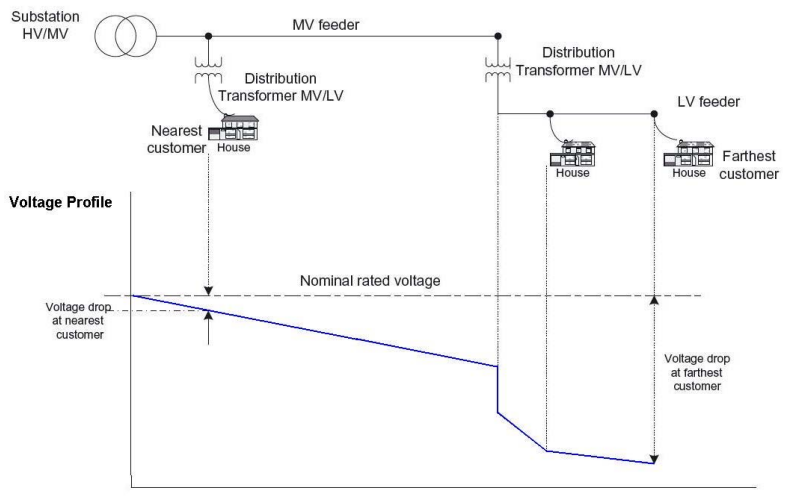

Per unit Length of feeder $(\%)$

Fig. 1. A typical voltage profile along a feeder in radial distribution network [2]

Maintaining the desired voltage at any point along the feeder is possible either by direct control of the voltage or by controlling the reactive power flow that in turn affects the voltage drop. In fact the reactive power flow creates voltage drop on inductive element of wires. So in order to keep the voltage always within certain limits, the reactive power flow and voltage control must be considered together, as we call it Volt/VAr control. For the voltage and reactive power control, these equipments are used: on-load tap-changer (OLTC) transformers, switched shunt capacitors and steps voltage regulators [3].

Voltage and reactive power control in general means the implementation of a proper coordination strategy among the available voltage and reactive power control equipments. Many Distribution Network Operators (DNOs) use the loss minimization objective to operate these equipments locally by using conventional controllers. The problem of voltage and reactive power control in distribution systems has been changed especially under smart grid concepts. The focus is more on automated distribution system, more on real time control and less on off-line setting control. The real time control aims to manage the capacitor and OLTC based on real time measurements and experiences versus the traditional offline setting control i.e to find a dispatch schedule for capacitor switching and OLTC changes based on a one day to several hours ahead load forecast [4].

Usually several voltage regulation and Var compensation devices are available on each feeder. Imagine that locally available measurements (voltage or current) are used for voltage and var control. The problem is that each device is controlled independently, so each control action might affect the performance of other devices. The consequence is that global actions yield inconsistent control actions and/or suboptimal results. This means that a coordinated approach is needed for optimal result. The coordination must be done centrally using a substation automation system or a DMS system. For such a coordinated Volt/Var optimal control we need: 1) two-way communication infrastructure, and 2) robust voltage and var optimization algorithm for handling large and complex distribution network [5].

\section{APPROACHES TO VOLT /VAR CONTROL}

It has been motivated in previous chapters that the main purpose of VVC is to maintain acceptable voltage level at all points along the distribution feeder under all loading conditions [6].

As minimum requirement for voltage control is the possibility for the operator to maintain the voltage on the feeder at an acceptable range by changing the position of moveable tap changer on a voltage regulator or tap changing transformer.

The acceptable ranges are based on international voltage regulation standards which are used by distribution utilities around the world. In the North America, most of distribution utilities follow the ANSI American National Standards Institute voltage standards (ANSI C84.1-1995) [7]-[9]. The acceptable operational range of voltage is specified by ANSI at two locations on power systems:

- Service voltage: the interconnection point between the electrical systems of the supplier and the user, usually at the meter (where the utility is responsible).

- Utilization voltage: line terminal voltage of the equipment (which is the characteristics of the equipment).

In practice, the distribution utilities try to have delivery voltage in upper portion of the acceptable range. Since ANSI standards have some flexibility in the allowable delivery voltage, many utilities take that advantage and introduce the concept of Conservation Voltage Reduction (CVR).

The idea of implementing CVR is to reduce electrical demand by maintaining the delivered voltage to the customer in the lower portion of the acceptable range. This will result in reduction of energy consumption over time [10].

CVR concept works quite well for many types of loads. Practical implementation shows that CVR concept works best with resistive load (lighting and resistive heating) because power drawn proportionally decreases with the voltage squared [11].

Other investigations showed that many electrical devices operate more efficiently (using less power with reduced voltage). For example Motors can be considered as "constant power" devices and their efficiency improves for a small reduced voltage [12].

Though it must be mentioned that CVR concept does not work properly on some emerging load characteristics, for example the loss increase for inverter based loads (which have constant power behavior). This means that CVR concept must be applied with clear understanding of different types of loads 
available in distribution network [6].

Key characteristics of distribution VVC can be summarized as following [10]:

- Acceptable voltage level and voltage profile must be maintained at all points along the distribution feeder within all loading conditions.

- Acceptable power factor for each feeder must be maintained within all loading conditions.

- Operator override must be allowed and proper alarm/alert system must be available for failure of control devices.

- Feeder Reconfiguration must be properly handled

- Optimal coordinated control of all available Volt VAR devices must be provided, including selectable operating objectives.

- Reactive power control from connected distributed energy resources must be handled.

It is worth noting that above mentioned characteristics are ideal and target requirements for the distribution utilities. Available practical VVC function used by different utilities usually have some or most of above mentioned characteristics [13]. Here in this paper we review the most common approaches to VVC and provide an insight to the advantage and disadvantage of each approach.

According to literature, there are three main approaches to Volt VAR Control [14]:

- Standalone Voltage regulator and LTC control (Traditional VVC).

- SCADA VVO (or rule based VVO).

- Integrated Volt/Var control (DMS model based VVO).

\section{A. Standalone Voltage regulator and LTC controls (Traditional VVC)}

Figure 2 shows a general schematic of Standalone Voltage regulator and LTC control approach [6]. Traditional Volt/Var control is managed by controlling all available individual and independent regulating devices as following:

- Substation transformer load tap changers (LTCs) with voltage regulators.

- Line voltage regulators.

- Fixed and switched capacitor banks.

Control parameters are Power Factor, Load Current, Voltage and Var Flow. Based on the local conditions (such as voltage, load, reactive power), the single capacitor bank is switch on and off.

This approach satisfies the basic requirement of VVC objectives, but still has many limitations and disadvantages. In general the local operation of controlling equipments will not provide a global optimal operational output. System is not monitored, and operator cannot override the control actions whenever needed, since all control actions are based on local measurement. Switched capacitors banks can simply be out of service because of blown fuses, and due to lack of monitoring they will not participate in the Volt/Var control. Also this approach has no solution for handling the reconfiguration of the feeders. [14].

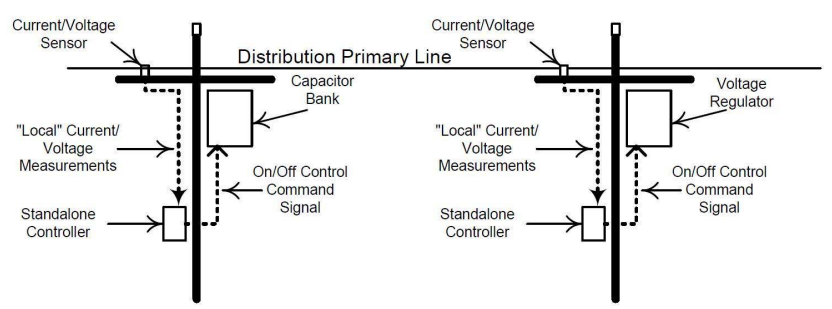

Fig. 2. Schematic of Standalone Voltage regulator and LTC control approach [6].

The main disadvantage of traditional VVC is the weakness of standalone controllers when distributed generators are present and the power flow direction is not necessarily from substation towards loads.

\section{B. SCADA (Rule based Controlled) Volt-VAR}

Figure 3 and 4 show the general schematic of SCADA controlled (so called Rule Based VVC) where the system components are:

- Substation Remote Terminal Unit

- VVO/CVR processor

- Switched Cap banks \& local measurement facilities

- Voltage regulators (LTCs), local measurement facilities

- Communication facilities

- End of line voltage feedback

This approach is the most common approach used for automation of VVC and many of distribution control center are equipped with DMS bases VVO function over the past 10 years. Substation RTUs are for monitoring and control and the $\mathrm{VVO} / \mathrm{CVR}$ processor is programmed with some "rules" for volt and VAR control. These predetermined rules are set based on operational experiences; for example switch the capacitor bank ON, if power factor is less than 0.95.

As it can be seen in figure 3 and 4, the SCADA controlled VVC is typically treated as two separate (independent) problem:

- VAR Dispatch (or power factor correction): for controlling the capacitor banks to improve power factor and reduce electrical losses (both in substations and on the feeders)

- Voltage Control: for controlling LTCs and/or voltage regulators for CVR purpose (to reduce demand and energy consumption)

In VAR Control (Power Factor Correction) part, the "candidate" capacitor banks for switching will be identified. The method is first to compare the rating of cap banks and choose the "candidate" cap bank which has lowest measured local voltage. Then switch ON the chosen cap bank to improve power factor and reduce the total electrical loss.

One Numerical example from [14] is presented in figure 3 to show the stages of power factor control in this approach. Starting from the point with lowest voltage profile (blue line) first the capacitor $\mathrm{N}$ is candidate to be switched ON. First row in the Table 1 represents the power flow and the power factor 
when no capacitor is in service. Then next capacitor switched to $\mathrm{ON}$ and the process continues to reach the best PF and lowest loss.

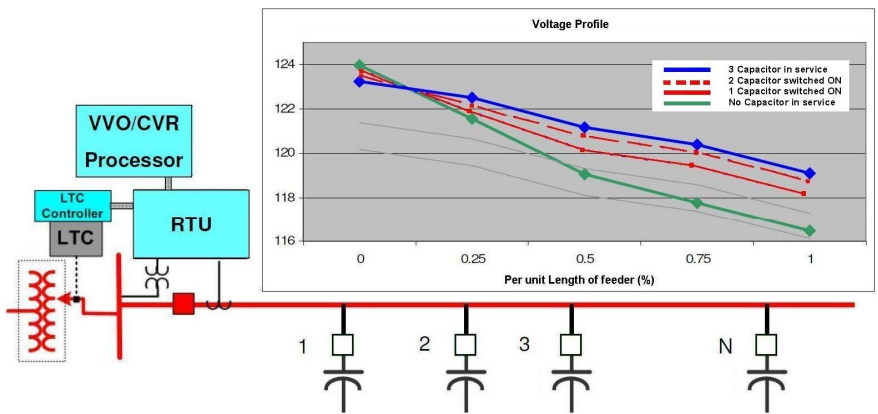

Fig. 3. SCADA controlled VVC, first part: VAR Dispatch (or power factor correction) [14].

TABLE I

NUMERICAL RESULTS OF VAR DISPATCH SCADA [14]

\begin{tabular}{|l|l|l|l|l|l|}
\hline Scenario & \multicolumn{1}{|c|}{$\begin{array}{c}\text { Status of } \\
\text { Capacitor banks }\end{array}$} & $\begin{array}{c}\text { P } \\
{[\mathbf{k W}]}\end{array}$ & $\begin{array}{c}\text { Q } \\
{[\mathbf{k V a r}]}\end{array}$ & PF & $\begin{array}{l}\text { Loss } \\
{[\mathbf{k W}]}\end{array}$ \\
\hline 1 (blue) & All cap OFF & 3846 & 1318 & 0.946 & 96 \\
\hline 2 (solid red) & $\begin{array}{l}\text { 1 cap ON } \\
\text { All other OFF }\end{array}$ & 3880 & 920 & 0.973 & 91 \\
\hline 3 (dash red) & $\begin{array}{l}\text { 2 cap ON } \\
\text { All other OFF }\end{array}$ & 3920 & 687 & 0.985 & 89 \\
\hline 4 (green) & $\begin{array}{l}\text { 3 cap ON } \\
\text { All others OFF }\end{array}$ & 3940 & 532 & 0.991 & 88 \\
\hline
\end{tabular}

In Voltage control part, if the voltage at head end of the feeder exceeds from LTC Set-point, then the voltage must be decreased. Starting from the operating point where all 3 capacitors are in service (scenario 4 of figure 3 ) and by adjusting the tap changer positions, it is possible to improve the voltage profile as it is shown in figure 4. By CVR strategy, the total amount of reduction in active power will be equal to $-41 \mathrm{~kW}(1.05 \%)$ and for reactive power will be $-809 \mathrm{kVAR}$ $(61 \%)$. So in total the power factor will improve around +.045 and total loss will decrease around $8 \%$ [14]. The result of voltage profile improvement is shown in figure 4 i.e. before and after tap changer adjustment.

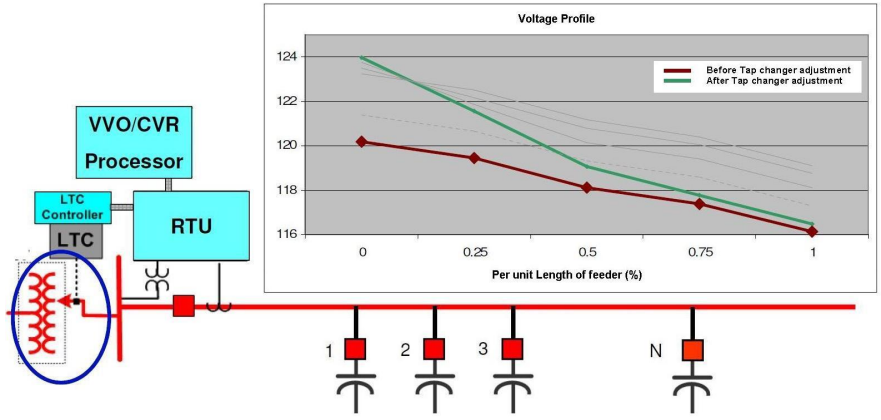

Fig. 4. SCADA controlled VVC, second part: Voltage Control [14]

This approach improves the efficiency comparing to the standalone controllers. SCADA provides proper self monitoring and in case of failure of controlled equipment, the operator will receive notice. In this approach remote measurements are included in the "rules", so smaller margin of safety is needed compared to standalone controller.
In return SCADA VVC is more complicated and requires extensive communication facilities. The main disadvantage of this approach is that it cannot handle the changing feeder configuration because the defined rules are fixed in advance. Though the overall efficiency is improved versus traditional approach, but it is still not necessarily the optimal under all conditions. This approach also cannot adapt very well to when larger DG are integrated into distribution network [14].

\section{Distribution Model based (integrated Volt-VAR Control and Optimization)}

This approach is the most advanced VVO approach which develops and executes a coordinated "optimal" switching plan for all voltage control devices in the system. The major objective functions which are achieved by this approach are minimization of loss and minimization of energy consumption or combination of both of them.

Since the number of switching of capacitor bank and tap changer movements are directly effecting efficient lifetime of these equipment, it is desired to bias the results to minimize tap changer movement and capacitor bank switching [15].

Figure 5 shows the IVVC components and sequence of control devices [16].

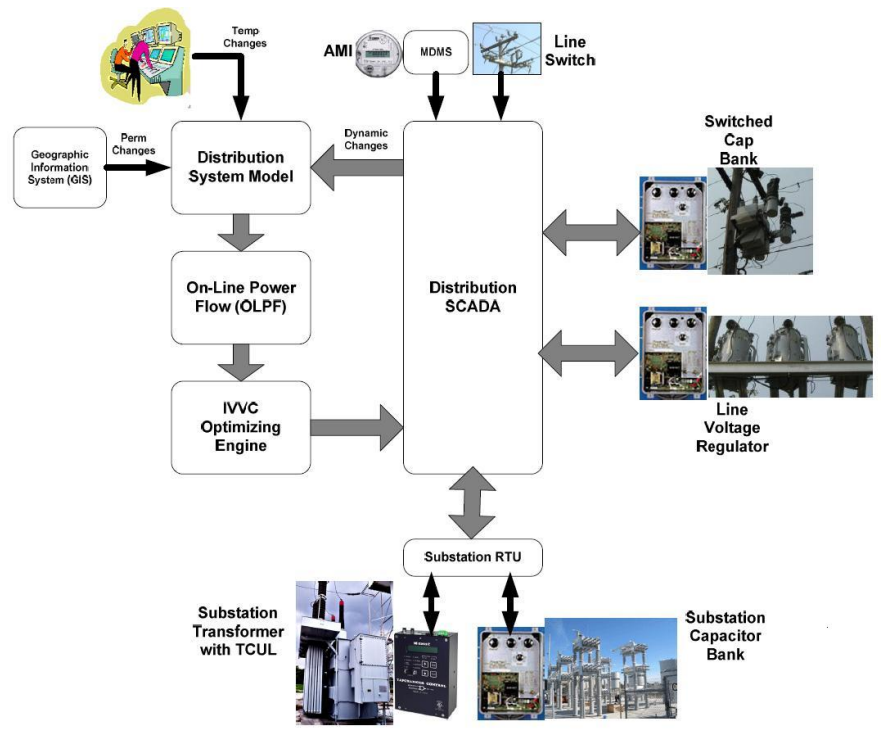

Fig. 5. DMS model based VVC (details of IVVC control components [16]

IVVC uses available real time measurements and distribution system model and by a proper on-line power flow calculation function, it is possible to calculate the electrical conditions and total loss and other parameters over the whole network. An "optimizing engine" is needed to calculate the optimal set of control actions for all control equipment. These control actions will be sent to controllers via SCADA.

DMS-Based Volt VAR optimization is a fully coordinated control and potentially can provide the optimal solution. It is able to handle complex feeder arrangements during feeder reconfiguration. Some of available DMS base VVO function can model the integration and effects of distributed generation and other emerging grid elements. 
In return, it is very expensive to implement and operate and is not very scalable to be used for one single station or feeder.

\section{Optimization Method Selection}

One major challenge in Volt/Var optimization problem is to select the optimization method and algorithm. The correct selection optimization method depends on two factors:

a) The nature of the objective functions and constraints,

b) the nature and number internal treatment of the control variables.

From a mathematical point of view the Volt/Var Control optimization problem is a minimization problem with inequality constraints. By solving power flow, we can calculate the objective function with given settings of the control variables while satisfying the constraints and limits. Three main types of objective function may be formulated as follows:

- Distribution subsystem active power loss - sum of the losses in lines, transformers and capacitors.

- Distribution subsystem power demand - sum of the power losses and customer demand.

- Minimum number of control actions.

While the main constraints are:

- Voltage at each distribution transformer primary bus

- Voltage at each distribution transformer secondary bus

- Current flow in each line or transformer

- Power factor at the distribution substation bus and feeder

- Reactive power at the distribution substation bus.

It is possible in many cases that all available control resources are not sufficient to satisfy all above mentioned constraints, so a compromise solution must be made. Since all the constraints are not necessarily rigid (hard) at all times, it will be practical to relax some of the constraints in order to satisfy the more critical other constraints, leading to a "suboptimal" solution for objective function [13].

Distribution system controls actions (the capacitor and tap control) are discrete, but the mathematical optimization procedures can consider controls as either continuous or discrete variables. So a common approach for selecting the method for optimization is to establish the Volt/Var control optimization problem as a discrete (integer) programming problem with nonlinear objective function and soft inequality constraints [13].

References [19]-[25] explain the analytical techniques to solve the VVO problem, where they have considered radial distribution system for simplicity and the impact of the detailed system component models on the solution is not taken into account.

In the last 10 years, some other techniques have been introduced to solve the problem, including the rule based techniques [26]-[31] and Meta-heuristic techniques [32]-[35] including genetic algorithms, simulated annealing, particle swarming, etc). It must be noted that all these approaches avoid the modeling complexity and are limited in solving small scale problems and mostly for off-line applications [5].
The main challenge for solving the optimization problem is the extremely large number of search space for optimized solution. All the above mentioned different methods are trying to propose an efficient and at the same time robust enough algorithm to handle the large search space.

If the number of shunt capacitor is $\mathrm{SC}$ and number of controlling tap changer is TP, the total search space for the optimal device settings that minimize the cost of the objective function is $\left(2^{\wedge} \mathrm{SC} \times 33^{\wedge} \mathrm{TP}\right)^{\wedge} \mathrm{TD}$ for every time domain. In fact 2 is status of capacitor (On/Off) and 33 is the number of available tap positions (from -16 to 16) for each LTC and TD stands for the number of time domain in one 24-hour optimization time. This is the reason that a robust optimization algorithm is needed for handling such large number of search space for the global optimum [15]. As a numeric example if we have $\mathrm{SC}=20, \mathrm{TP}=10$, and $\mathrm{TD}=288$ (the number of 5 minute time domain in 24-hours) then the number of combinations of control device settings is "Infinite". Or even if we reduce the number of devices to $\mathrm{CB}=10, \mathrm{TP}=4$ (only 4 tap instead of 33 tap position) and $\mathrm{TD}=7$, the resulting search space is greater than $1.6455 \mathrm{E}+63$ [17].

\section{FUTURE OF VOLT/VAR CONTROL/OPTIMIZATION}

Current implementation of Volt/VAR control/optimization used by distribution utilities show that VVO have great proven value and is one of the fundamental requirements of DMS functionality. Also recent technology advancement in ICT and communications and also integration of smart meters can accelerate the implementation of VVO even beyond the scope of Volt/VAR control [18].

Figure 6 shows a summary of future Volt/VAR control/optimization trends [6].

To summarize the future trends in evolution of $\mathrm{VVC} / \mathrm{VVO}$ we can mention the following items:

- Integration of emerging technologies and controls

- Integration of distributed energy resources, solar PV, etc

- Integration of distributed Energy storage systems

- Integration of Electric Vehicles, various charging.

The main challenge is to consider the effect of above mentioned technologies and scenarios into control objectives and trying to solve the optimization problem with larger dimensions of objective and constraints.

\section{CONCLUSION}

A centralized Volt/Var Control and optimization is one of the most desirable and important functions within Distribution Automation systems and DMSs. In this review paper, we have reviewed the existing and recent techniques and algorithms for advanced VVO applications and have identified the most important requirements for integrated Volt/Var control and optimization function for distribution management systems within smart grid concept. The main challenge for this problem is to consider the evolution in power system elements when we have many different forms of distributed energy resources and emerging technologies and controls. The other important issue in VVO problem is the capability of 
computation algorithms for real time implementation in today distribution control centers. There are several successful of VVO function but this field is still subject to new paradigms and challenges.

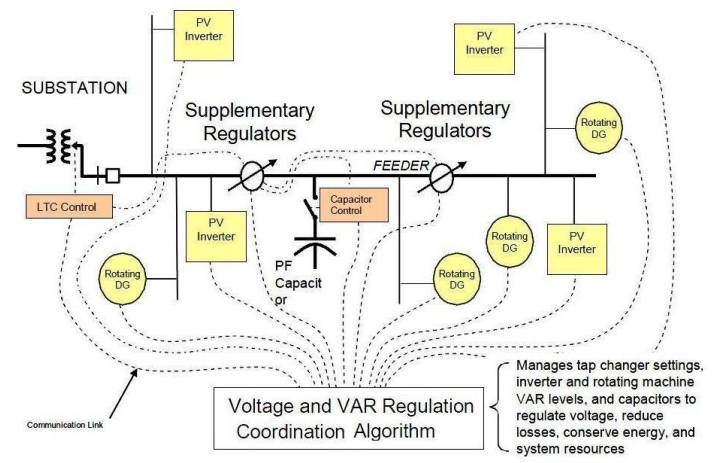

Fig. 6. Summary of future trend in Volt/VAR control/optimization trends [6]

\section{REFERENCES}

[1] Electric Distribution Systems, Sallam, A. Malik, O., Wiley-IEEE Press , 2011 , ISBN : 9780470943854

[2] J. J. Burke, Power Distribution Engineering: Fundamentals and Applications, Marcel Dekker, 1994

[3] T.A. Short, Electric Power Distribution Handbook, CRC Press LLC, 2004.

[4] Voltage Control and Voltage Stability of Power Distribution Systems, in the Presence of Distributed Generation, FERRY AUGUST VIAWAN, PhD Thesis, Chalmers university, ISBN 978-91-7385-060-5

[5] X. Feng, W. Peterson, and F. Yang, "Implementation of control center based voltage and var optimization in distribution management system," IEEE PES Transmission and Distribution Conference and Exposition, 2010, pp. 1-6, 2010.

[6] Smart Distribution Systems for a Low Carbon Energy Future Workshop, CIRED workshop, 6 June 2011, Frankfurt, Germany. Available online at:http:/grouper.ieee.org/groups/td/dist/da/doc/2011\%20CIRED\%20Pan el\%20Tutorial\%20binder_AH.pdf

[7] Electric Power Distribution Handbook, T. A. Short, CRC Press 2003, Print ISBN: 978-0-8493-1791-0

[8] ANSI C84.1-1995, American National Standards for Electric Power Systems and Equipment - Voltage Ratings $(60 \mathrm{~Hz})$.

[9] ANSI Std . C84.1 - 2006 . For Electric Power Systems and EquipmentVoltage Ratings $(60 \mathrm{~Hz}) .2006$

[10] R. Uluski, "VVC in the Smart Grid era," Power and Energy Society General Meeting, pp. 1-7, 2010.

[11] "Evaluation of Conservation Voltage Reduction (CVR) on a National Level"; PNNL report; July 2010.

[12] The Effects of Reduced Voltages on the Efficiency of Electric Loads, Chen, M.S. , Shoults, R. , Fitzer, J. , Songster, H., IEEE Transactions on Power Apparatus and Systems, July 1982

[13] I. Roytelman and B. Wee, "Volt/Var control algorithm for modern distribution management system," IEEE Transactions on Power Systems, vol. 10, no. 3, pp. 1454-1460, 1995.

[14] Proof of Concept Process for Volt/VAR Control and Optimization, Bob Uluski, EUCI Seminar - Chicago, IL September 26, 2011

[15] M. Krok, "A coordinated optimization approach to Volt/VAr control for large power distribution networks," American Control Conference (ACC), 2011, pp. 1145-1150, 2011.

[16] R. Uluski, "VVC in the Smart Grid era," Power and Energy Society General Meeting,, pp. 1-7, 2010.

[17] H. Johal, W. Ren, Y. Pan, and M. Krok, "An integrated approach for controlling and optimizing the operation of a power distribution system," in ISGT Europe, 2010 IEEE PES, 2010, pp. 1 -7.

[18] Volt/Var Control (VVC) and Volt/Var Optimization (VVO), Xiaoming Feng, John Barnick, EUCI Seminar - Chicago, IL September 26, 2011

[19] J. J. Grainger and S. Civanlar, "Volt/Var Control on Distribution Systems with Lateral Branches Using Shunt Capacitors and Voltage
Regulators-Part 1: The Overall Problem,” IEEE Trans. Power Apparatus and Systems, vol. PAS-104, no.11, pp. 3278-3283, Nov. 1985.

[20] S. Civanlar and J. J. Grainger, "Volt/Var Control on Distribution Systems with Lateral Branches Using Shunt Capacitors and Voltage Regulators-Part 2: The Solution Method", IEEE Trans. Power Apparatus and Systems, vol. PAS-104, no.11, pp.3284-3290, Nov. 1985.

[21] R. Baldick and F. F. Wu, "Efficient Integer Optimization Algorithm for Optimal Coordination of Capacitors and Regulators," IEEE Trans. Power Systems, vol.5 no.3, pp.805-812, Aug. 1990.

[22] F.C. Lu and Y.Y. Hsu, "Reactive Power/Voltage Control in a Distribution Substation Using Dynamic Programming," IEE Proceedings- Generation, Transmission and Distribution, vol. 142, no. 6, pp. 639-644, Nov 1995.

[23] F.C. Lu and Y.Y. Hsu, "Fuzzy Dynamic Programming Approach to Reactive Power/Voltage Control in a Distribution Substation," IEEE Transactions on Power Systems, vol. 12, no. 2, pp. 681-688, May 1997.

[24] I. Roytelman, B. K. Wee, and R. L. Lugtu, and T. M. Kulars, "Volt/Var Control Algorithm for Modern Distribution Management System," IEEE Trans. Power Systems, vol.10, no.3, pp.1454-1460, Aug. 1995.

[25] I. Roytelman, B. K. Wee, and R. L. Lugtu, T. M. Kulars, and T. Brossart, "Pilot Project to Estimate the Generalized Volt/Var Control Effectiveness," IEEE Trans. Power Systems, vol. 13, no.3, pp.864-869, Aug. 1998.

[26] S. J. Cheng, O. P. Malik, and G. S. Hope, "An Expert System for Voltage and Reactive Power Control of a Power System," IEEE Trans. Power Systems, vol. 3, no.4, pp.1449-1455, Nov. 1988.

[27] M.M.A. Salama and A.Y. Chikhani, "An Expert System for Reactive Power Control of a Distribution System- Part 1: System Configuration," IEEE Trans. on Power Delivery, vol. 7, no. 2, pp 940-945, Apr 1992.

[28] G. Ramakrishna and N.D. Rao, "A Fuzzy Logic Framework for Control of Switched Capacitors in Distribution Systems," in Proc. Canadian Conference on Electrical \& Computer Engineering, Montreal, Canada, September 1995, pp. 676-679.

[29] G. Ramakrishna and N.D. Rao, "Fuzzy Inference System to Assist the Operator in Reactive Power Control in Distribution Systems," IEE Proceedings- Generation, Transmission and Distribution, vol. 145, no. 2, pp. 133-138, March 1998.

[30] V. Miranda and P. Calisto, "A Fuzzy Inference System to Voltage/Var Control in DMS- Distribution Management System," in Proc. 14th Systems Computations Conference, Sevilla, Spain, June 2002.

[31] Y.Y. Hsu and F.C. Lu, "A Combined Artificial Neural Network-Fuzzy Dynamic Programming Approach to Reactive Power/Voltage Control in a Distribution Substation," IEEE Transactions on Power Systems, vol. 13, no. 4, pp. 1265-1271, November 1998.

[32] R.H. Liang and Y.S. Wang, "Fuzzy-Based Reactive Power and Voltage Control in a Distribution System," IEEE Transactions on Power Delivery, vol. 18, no. 2, pp. 610-618, April 2003.

[33] Z. Hu, X. Wang, H. Chen and G.A. Taylor, "Volt/Var Control in Distribution Systems Using a Time-Interval Based Approach," IEE Proceedings- Generation, Transmission and Distribution, vol. 150, no. 5, pp. 548-554, September 2003.

[34] T. Niknam, A.M. Ranjbar and A.R. Shirani, "Impact of Distributed Generation on Volt/Var Control in Distribution Networks," in Proc. IEEE PowerTech Conference, Bologna, Italy, June 2003.

[35] A. Borghetti, M. Bosetti, S. Grillo, S. Massucco, C.A. Nucci, M. Paolone, F. Silvestro, "Short Term Scheduling and Control of Active Distribution Systems with High Penetration of Renewable Resources", IEEE Systems Journal, Special Issue on "Identification and Control of Sustainable Energy Systems", Vol 4, Issue 3, Sep 2010, pp. 313-322. 